\title{
JOURNAL OF LARYNGOLOGY
}

\section{AND RHINOLOGY.}

\begin{tabular}{lll}
\hline Vol. III. DECEMBER, I889. & No. I2. \\
\hline
\end{tabular}

The Editors do not hold themselies resfonsible for opinions expressed by contributors.

\section{INAUGURAL ADDRESS.}

\section{Delivered at the First Meeting of the Second Session of the British} Laryngological and Rhinological Association, November, 1889,

By Philip Suyly, M.D., of Dublin,

President of the Association.

\section{GentLEMEN,-}

My first duty on taking the chair to-day is to thank you for coming here--many of you from distant parts of the country, and at considerable inconvenience.

My second is to thank you for having placed me in this post of honour.

It is very encouraging to find that Irishmen are not forgotten, even when they remain in the old country. In every department of the State, and in all the professions, you have Irishmen who have done well for themselves and their country. It is a rare honour for an Irishman to be elected president of a London society. This year a similar honour has been conferred by another Society on a Dublin man-my friend, Dr. Macan, President of the Gynxcological Society.

There are strong bonds that bind men together-but there are forces that separate.

One of our most distinguished Viceroys, in an after dinner speech in Dublin, said, some few years ago--" There are laws that bind England "and Ireland together, which no parliament can repeal or alter-the laws "of nature."

These laws have not yet been codified, nor are they to be found in any blue book.

In the case of our Association, our bond of union must be our common interest in the search after truth. We must ever bear in mind that truth is "many sided." Truth is not a machine to be constructed-to be set going at will-to be measured, and to be directed in the way she should go. No ; she is a beauty, who must be loved and worshipped.

Our Association was brought into existence last year with the object of bringing all the specialists of the United Kingdom together. Sir 


\section{The Journal of Laryngology and Rhinology.}

Morell Mackenzie, in his address last year, said-" A few years ago such "a society would have been impossible, not from lack of objects o "scientific activity, but from want of men." Now laryngology is in such a flourishing condition, that we can survive an exodus from our Association, and still exist.

The efforts made to bring back those who left the Association, I regret to say, have not been successful.

Your Association, however, has a good backbone, and is still enlarging its list of members in quite sufficient numbers to assure us of future success

My predecessor, in his eloquent address last year, said- "The Society, "whose formal entrance on life we are met here to-night to celebrate, is, "I feel, destined to play a most important part in the furtherance of our "knowledge of discases of the upper air-passages, and our ability to "prevent and cure them."

To-day we meet to celebrate the completion of a year of real good work done, and to begin a new year in good hope-and "great expectations."

Though the Association is intended for the advance of laryngology, we are not all specialists, and we welcome into our ranks all who use the laryngoscope in their daily practice-as they use their stethoscope, and their thermometer.

The position of laryngology in the medical world is in some degrees granted, but not fully, as yet. The time is not far off. Every year shows that laryngology is taking its place, not only as a speciality, but also as an integral part of the profession.

I am sure that laryngology will soon form an essential part of the medical student's education, and will be required as a branch of medicine and surgery, as other special subjects are at the final examinations, for admission to our profession.

A very important step has been taken in this direction by our American cousins. A few weeks ago I received a synopsis of a course of clinical lectures on diseases of the throat and nose, to be delivered in the theatre of the Vanderbilt Clinic, College of Physicians and Surgeons, New York, by Professor Lefferts, during the session of $1889-90$.

Sir Morell Mackenzie last year gave you hope of work to be done. I have the pleasing task of congratulating on the work that has been done. The papers were interesting, and the discussions were full of good sense, and conducted with good temper.

The first paper was on the "Treatment of nervous affections of the Throat." This paper was chiefly occupied by the use of galvanism, and the comparative advantages of the different currents for aphonia. With regard to this subject, we may repeat the words of the Famulus in Faust, "I already know much, but I would fain know all"; but unlike him we know that we do not know, much that we want to know.

The advances in electrical knowledge is so rapidly on the increase, that the news of last month is almost ancient history this month.

The discussion on this paper was very full and satisfactory. One expression I find fault with-an expression used by several of the speakers, so I presume it conveyed some meaning to them-" The moral effect of 


\section{The Journal of Laryngology and Rhinology.}

the galvanic current." I can understand the moral effects of a good blackthorn stick in an Irish fair, if the man who carries it looks like using it, if needs be, or of a six-shooter in the Western States. I do not believe in any moral effect in electricity. It is a useful stimulant, and certainly prevents muscular wasting when carefully used.

"Anosmia" was very well treated by Dr. Dundas Grant. He alluded to the action of cocaine improving the sense of smell when prudently used in the treatment of anosmia. This observation has been confirmed by subsequent observations.

Dr. Hunter Mackenzie read a paper on a branch of a very large subject, namely, "On the influence of certain medical agents on the Bacillus of Tubercle in Man." He purposely reserved for future discussion the indications for surgical treatment in laryngeal phthisis. In the course of the discussion several members spoke very hopefully of local treatment in cases of phthisis laryngea, especially with regard to the use of lactic acid and menthol.

Whether it be finally settled that the tubercle bacillus is the cause of the disease, or that the diseased structure provides a suitable habitation for the bacillus, there is no doubt that we have means of contending with this fearful disease, in its early stages, which we knew nothing of a very few years ago.

Dr. Norris Wolfenden's paper on "Cancer of the Thyroid Gland," "A "case of Nasal Calculus," by Dr. F. M. Hunt, and a paper on the "Physics " of certain Nose and Throat diseases" brought the meeting of November I 4 th to an end.

"The relative merits of early and late Tracheotomy in chronic diseases of the Larynx," was the title of a paper read by Mr. L. Browne. He gives some useful rules for guidance in selecting cases for operation.

My belief in this connection is that each case must be decided on its own merits, and that even in the last stages of phthisis laryngea many days of torture may be saved by an operation which itself gives very little pain or shock.

These operations should be done with Sir James Paget's dictum well in mind. A surgeon should never be actively useless, and need not regard the unkind comments of the medical brother alluded to in the paper, whose

$$
\text { "Praise dispraises, whose dispraises praise!" }
$$

(Giles Fietcher.)

The next paper was by Dr. Charles IVarden, of Birmingham, on "Parosphresia and Parageusia."

Mr. Stoker gave a very useful paper on "Anæsthetics in operating on the Throat and Nose." I may mention in passing, that the late Sir Philip Crampton operated in the Meath Hospital many years ago, placing the patient in very much the same position so well described by Mr. Stoker in his paper. The position (namely, a wcdge-shaped cushion under the shoulders, so as to let the top of the head rest on the table) is not a very convenient one. The reason assigned for its adoption is that blood may get into the larynx during deep anæsthesia; the fact that this does not occur was pointed out by the late Maurice H. Collis, of the Meath 


\section{The Journal of Laryngology and Rhinology.}

Hospital, and has since been verified by every surgeon who operates on cleft palates.

This meeting was brought to a close by a paper on some new remedies in diseases of the throat.

June 26th. Mr. Mark Hovell and Dr. Wright Wilson introduced the subject of diseases of the glandular structures of the pharynx and nasopharynx. This is a most interesting subject, and our means of diagnosis, and our knowledge of what to do when our diagnosis is made, are increasing every year. Some idea of the importance of this subject may be formed by the statement of a recent writer: "In the post-nasal region the cure of adenoid vegetations has resulted in the prevention of deafness to such an extent that there are, probably, at least 100,000 persons now hearing well who, had it not been for Dr. Meyer's valuable discovery, twenty years ago, would be hopelessly deaf. I hope we may have another such paper this session from these gentlemen.

The President gave a most interesting paper on "Gouty Sore Throat." True gout in the throat is an extremely rare condition, as Sir Morell Mackenzie points out, but there is a gouty condition of the throat as well as of other parts of a gouty subject, to which Sir James Paget gives the name, in his lectures, "incomplete gout." This condition is more frequently found.

Prof. Collier brought the session to a close with an interesting account of the hyo-epiglottic membrane.

This is a very brief note of the work done by your Association. Let us strive to do more this session. It is not necessary to strive after novelty-though novelty is not to be despised-nor yet to fear bringing forward a subject of interest because others may have already spoken or written on the same subject. It is very useful to go over old ground, and, even in a well reaped field, good grain may be gathered by careful gleaning.

There are several subjects I should like to hear discussed by this Association-for, example, the use and abuse of the galvano-caustic. It is now so much used, not only in the throat, but in the nose and ear. The subject has an added interest in the connection of other diseases with these organs. For example, the connection of various otherwise incurable neuralgias with disease in the nose, which have been cured by the galvanocautery; also the connection of the nose with the thyroid body in Graves' disease, as pointed out from different points of vicw by Mr. Stoker and by Dr. Felix Semon.

The opinion of the members as to how much may be done with safety, how little is cffective, would be of great value. The directions in some of the books seem to me to be rather violent. I am sure better results may be obtained by gentle means, and thus avoid what are called unfortunate cases, such as the case reported by Werner (in the JOURNAL OF LARYNGOLOGY AND RHINOLOGY, Vol. II., p. 43I), in which " the patient was only saved by making compression of the carotid for ten days," bleeding having come on five days after the treatment of an hypertrophied tonsil.

In this, as in other departments of surgery, there is a temptation to heroic treatment. "If I do not do it, someone else will," as Sir William Fraser, Bart., reports a saying of the Duke of Wellington. He who in war fails 


\section{The Journal of Laryngology and Rhinology.}

to do what he undertakes, may always plead the accidents which invariably attend military affairs, but he who declared a thing to be impossible, which is subsequently accomplished, registers his own incapacity.

On the other hand, we should remember that "by trying to do better "we often mar what's well."

Among other subjects for discussion, I would mention the condition of the throat in such diseases as diabetes, and in albuminuria, following in much the line of Sir Morell Mackenzic's paper on gout. And also the influence other organs have on the throat, not directly or obviously connected with it in some such way as we know the condition of the liver has on the blood-ressels of the nose as well as on the hemorrhoidal veins.

In the nomenclature I would deprecate the use of Greek names, and particularly the combination of Greek and Latin names. I must confess my admiration for the way the Germans call a spade a spade.

To give an example of the importance of going over the ground already passed over, I would in a few words call your attention to the action of the epiglottis.

The epiglottis stands between the tongue and the larynx. The larynx is open ; during the act of swallowing the larynx must be closed. Therefore, the epiglottis is a lid. It closes over the larynx, and the subject is finished.

In this case I may quote the words of the Duke of Argyle on another subject:- "Which is a curious example how preconceived theories "founded on false analogies will vitiate our observation of the commonest "facts in nature."

No laryngologist believes this, though we go on saying it, much in the same way as we say the sun rises and sets, Americans speak through their noses, or that, when a small boy turns his heels up in the air, he has turned head over heels.

These expressions we use every day, and no one complains, because we all know what is meant.

When, however, a scientific book quite recently published, says at page 63 , that "the special office of the epiglottis is to close tightly over "the larynx during the passage of food into the pharynx," it is time to object. Also Quain's Anatomy says: "But during the act of swallowing " it is carried downwards and backwards over the entrance into the larynx, "which it covers and protects." Gray's Anatomy says : "But during" "deglutition it is carried downwards and backwards so as to completely "close the opening into the larynx." In Fraenkel's Article in Ziemssen's Encyclopædia: "The upper side of the epiglottis never touches the "posterior wall of the pharynx when it is laid backwards, a position which "it assumes during each act of deglutition."

Doctor Howard also speaks of "raising the epiglottis"-and Doctor Dwyer, of New York, of "hooking forward the epiglottis with his left fore-finger" when describing the operation of intubation.

I make these quotations merely to show that though the sense is gone the words are still used and may mislead.

So long ago as Magendie's time the lid action of the epiglottis was doubted. 


\section{The Journal of Laryngology and Rhinology.}

Both Lewin, of Berlin, and Semeleder, of Vienna, pointed out anddemonstrated with the laryngoscope that the epiglottis may be completely destroyed, and its total absence not be even suspected by the patient.

Prof. Hyrtl, of Vienna, says in his "Handbuch Topograph Anatomie," p. 87 :- "The epiglottis does not close the opening into the larynx during " the act of swallowing, as is falsely believed-and serves in noway for that "purpose-of sliding over the cavity like a drawbridge." He also mentions several cases in which the absence of the epiglottis was only discovered after death. Healso says- - "Let us pass the fingerfar enough back, "we come not on the anterior but on the posterior surface of the epiglottis."

There are manyother reasons which prove the truth of these statements, which Prof. Hyrtl published so many years ago-in the year 1857-with which I need not trouble you.

The action of swallowing may be described thus:-The glottis is raised towards the base of the tongue, the arytenoids are drawn together, the epiglottis is drawn into the fossa prepared for it in the base of the tongue, at the same time projecting the laryngeal end towards the arytenoids. The meeting of these three bodies closes the cavity of the larynx, and the closed larynx looks exactly like a very large leech-bite. The morsel of food passes over the base of the tongue and the laryngeal aspect of the epiglottis, and the rounded smooth surfaces of the two arytenoids into the œsophagus.

In conclusion, I would once more take up the words of my predecessor in this chair, and say to the members of this Association, "whilst de"voting yourselves to this speciality, continue to practise general medicine " and surgery."

I would further say to the profession in general, adopt the laryngoscope in your general practice, and use it as you now do your stethoscope and thermometer.

Last of all, remember that medicine-large and noble as it is-is only after all, a branch of natural science, and should be approached in a philosophic spirit.

Study Nature with an earnest and loyal spirit, and she will give you an ample reward. In the words of an American poet-

\footnotetext{
"For this is Nature's largess-color, tone,

"Splendor of land and sea-

"All that she once reveals becomes thine own,

"For days that are to be,"
}

(Francis L. Marr, Harpur, August, 1889.) 